\title{
M.-E. Michel-Beyerle (Editor)
}

\section{Reaction Centers of Photosynthetic Bacteria}

Feldafing-II-Meeting

With 165 Figures

Springer-Verlag Berlin Heidelberg NewYork London Paris Tokyo Hong Kong Barcelona 
Professor Dr. MAria-ElisabetII Michel-BeyerLl:

Institut für Physikalische und Theoretische Chemic

Technische Universität München

Lichtenbergstraße 4

W 8046 Garching, FRG

ISBN 3-540-53420-2 Springer-Verlag Berlin Heidelberg NewYork
ISBN 0-387-53420-2 Springer-Verlag NewYork Berlin Heidelberg

This work is subject to copyright. All rights are reserved, whether the whole or part of the material is concerned, specifically the rights of translation, reprinting, re-use of illustrations, recitation, broadcasting, reproduction on microlilms or in other ways, and storage in data banks. Duplication of this publication or parts thereof is only permitted under the provisions of the German Copyright Law of September 9.1965, in its current version and a copyright fee must always be paid. Violations fall under the prosecution act of the German Copyright Law.

(C) Springer-Verlag Berlin Heidelberg 1990

Printed in Germany

The use of registered names, trademarks, etc. in this publication does not imply, even in the absence of a specific statement, that such names are exempt from the relevant protective laws and regulations and therefore free for general use.

2131/3020-543210 - Printed on acid-free paper 


\section{Preface}

The workshop on "Structure and Function of Bacterial Reaction Centers" was held from March 24-26, 1990, to a day five years after the first meeting, at the Hotel "Kaiserin Elisabeth" in Feldafing, Bavaria (F.R.G.). The ' 85 workshop, on international stage quoted as the "Feldafing-Meeting" (Vol.42, Springer Series in Chemical Physics), had been dominated by the fresh impression of the three-dimensional structure of the reaction center from the photosynthetic bacterium Rhodopseudomonas viridis. The main emphasis in the follow-up meetings, 1987 at Cadarache (Vol.149, NATO ASI Series A: Life Sciences, Plenum Press 1988) and this year's "Feldafing-II", was put on the central issue of reaction center function. The reaction center is not only a paradigm for one of the most important light-transforming machineries in biology. Due to its detailed structura! characterization, it has also become the best-defined supramolecular electron donor/acceptor-system and offers unprecedented opportunities for the study of basic questions of electron transfer and protein dynamics.

Safely rooted in the crystal structure of the reaction center of meanwhile two bacterial organisms, the present compilation of invited papers points in a self-evident way at the different lines of developments of a still vividly expanding field. The abundance of open questions initiated novel methodological approaches bridging the gap from biochemistry, genetic engineering and complex spectroscopies to chemical modelling, molecular dynamics calculations and electron transfer theory. The material is organized into four Parts:

I. Native Reaction Centers : Structure and Spectroscopy

II. Native Reaction Centers : Electron Transfer Dynamics

III. Modified Reaction Centers : Effects of Mutagenic and Chemical Modifications

IV. Reaction Centers : Modelling of Structure/Function-Relationship

It should be noted that Part (II) gives a status-report on the still controversial problem of the primary charge separation mechanism. The ambiguities of the available dynamic data have stimulated innovative developments of spectroscopic techniques which are aiming at the combination of optimal time-resolution and highest sensitivity. External electric and magnetic 
fields shifting energy levels of cofactors have become necessary parameters in time-resolved absorption and fluorescence spectroscopy. The riddles in the reaction center function have also stimulated an explosively fast progress towards modifications along two lines, mutagenic replacement of single or multiple amino acids in the protein matrix and thermally induced replacement of cofactors against chemically modified ones. The expansion of the field in this direction is clearly manifested by the accumulation of contributions on modified reaction centers compiled in Part (III).

Parts (I) to (IV) altogether reflect the diversity of access to and different angles of looking at the same central object - the reaction center. This very employment of widely divergent and largely innovative methods is certainly a trade-mark of the fundamental contributions which Professor George Feher made to the area of elementary processes in photosynthesis. Thus, for the present level of our understanding of how the reaction center works, the community of researchers and "big game hunters in the field" owes him a great debt, and I am glad to dedicate this volume to him.

We like to express our gratitude to all the participants in the workshop for their contributions, and to the authors for the timely preparation of their manuscripts. I am especially indebted to my coworkers for their most valuable assistance and advice. As the main load and heavy responsibility for the success of the meeting was carried by Petra Kahıfuß, we have to thank her in particular.

In line with the '85 meeting, this workshop was organized under the auspices of the two Munich universities, the Technical University and the Ludwig-Maximilians-University, and the Max-Planck-Society. It was supported by the "Deutsche Forschungsgemeinschaft" within the frame of the "Sonderforschungsbereich 143". In this context we would like to thank especially Dr. Klaus Genius for his effective and continuous cooperation in helping to make this "Sonderforschungsbereich", and all activities around it, a success. 


\section{Contents}

PART I

Native Reaction Centers: Structure and Spectroscopy

F. REISS-HUSSON, B. ARNOUX, A. DUCRUIX, M. ROTH, M. PICAUD and C. ASTIER :

Reaction Center from Wild Type Y Rhodobacter sphaeroides:

Primary Structure of the $\mathrm{L}$ and M Subunits;

Carotenoid and Detergent Structures in the Three-Dimensional Crystals 3

Q. ZHOU, T. A. MATTIOLI and B. ROBERT

Probing Reaction Center Asymmetry Using Low Temperature

Absorption Spectroscopy of Rhodobacter sphaeroides

Reaction Centers Containing Bacteriopheophytin Anions ............11

A. VERMEGLIO, D. GARCIA and J. BRETON

Cytochrome Arrangement in Reaction Centers of Different Species

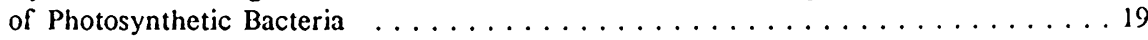

W. MÄNTELE, M. LEONHARD, M. BAUSCHER, E. NABEDRYK, J. BRETON and D.A. MOSS

Infrared Difference Spectroscopy of Electrochemically Generated

Redox States in Bacterial Reaction Centers ................... 31

E.J. LOUS, M. HUBER, R.A. ISAACSON and G. FEHER

EPR and ENDOR Studies of the Oxidized Primary Donor in Single

Crystals of Reaction Centers of Rhodobacter sphaeroides R-26

F. LENDZIAN, B. ENDEWARD, M. PLATO, D. BUMANN, W. LUBITZ and $K$. MÖBIUS

ENDOR and TRIPLE Resonance Investigation of the Primary Donor Cation Radical $\mathrm{P}_{865}^{+}$in Single Crystals of Rhodobacter sphaeroides

R-26 Reaction Centers

A. ANGERHOFER, J. GREIS, V. AUST, J.U. VON SCHÜTZ and H.C. WOLF

Triplet State ADMR of Bacterial Reaction Centers at Low Transition

Frequencies

S. BUCHANAN and H. MICHEL

Investigation of Quinone Reduction in Rhodopseudomonas viridis by

FTIR Difference Spectroscopy and X-Ray Diffraction Analysis . . . . . . . . 75

D.L. THIBODEAU, J. BRETON, C. BERTHOMIEU, K.A. BAGLEY,

W. MÄNTELE and E. NABEDRYK

Steady-State and Time-Resolved FTIR Spectroscopy of Quinones in

Bacterial Reaction Centers 
G.J. SMALL, R. JANKOWIAK, M. SEIBERT, C.F. YOCUM and D. TANG Spectral Hole Burning Studies of Photosystem II Reaction Centers:

Excited State Structure, Charge Separation and Energy Transfer Dynamics

C. KIRMAIER and D. HOLTEN

Evidence for an Inhomogeneous Distribution of Reaction Centers on the Timescale of the Primary Electron Transfer Events

U. FINKELE, K. DRESSLER, C. LAUTERWASSER and W. ZINTH Analysis of Transient Absorption Data from Reaction Centers of Purple Bacteria

K. DRESSLER, U. FINKELE, C. LAUTERWASSER, P. HAMM,

W. HOLZAPFEL, S. BUCHANAN, W. KAISER, H. MICHEL, D. OESTERHELT,

H. SCHEER, H.U. STILZ and W. ZINTH

Similarities of the Primary Charge Separation Process in the

Photosynthesis of Rhodobacter sphaeroides and Rhodopseudomonas viridis . . . . 135

G.H. ATKINSON, H. HAYASHI, M. TASUMI and S. KOLACZKOWSKI

Picosecond Resonance Raman Spectroscopy of Rhodobacter sphacroides

Reaction Centers . . . . . . . . . . . . . . . . . . . . . . . . . . . . . 141

S.G. BOXER, D.J. LOCKHART, S. FRANZEN and S.H. HAMMES

Electric Field Modulation of the Fluorescence Lineshape for

Photosynthetic Reaction Centers: A New Probe of the Primary

Electron Transfer Mechanism . . . . . . . . . . . . . . . . . 147

A. OGRODNIK, U. EBERL, R. HECKMANN, M. KAPPL, R. FEICK

and M.E. MICHEL-BEYERLE

One Step Electron Transfer to $\mathrm{P}^{+} \mathrm{H}^{-}$in Reaction Centers of

Rhodobacter sphaeroides Derived from Dichroic Excitation Spectra of

Electric Field Modulated Fluorescence Yield

M.G. MÜLLER, K. GRIEBENOW and A.R. HOLZWARTH

Energy Transfer and Charge Separation Kinetics in the Reaction Center

of Chloroflexus aurantiacus Studied by Picosecond Time-Resolved

Fluorescence Spectroscopy

R. FEICK, J.L. MARTIN, J. BRETON, M. VOLK, G. SCHEIDEL,

T. LANGENBACHER, C. URBANO, A. OGRODNIK

and M.E. MICHEL-BEYERLE

Biexponential Charge Separation and Monoexponential Decay

of $\mathrm{P}^{+} \mathrm{H}^{-}$in Reaction Centers of Chloroflexus aurantiacus

P. SEBBAN, P. PAROT, L. BACIOU, P. MATHIS and A. VERMEGLIO

Analog Effects of Low Temperature and Lipid Rigidity on the

Distribution of Two Conformational States of the Reaction Centers 
I. SINNING, J. KOEPKE and H. MICHEL

Recent Advances in the Structure Analysis of Rhodopseudomonas

viridis Reaction Center Mutants

M.M. YANG, W.J. COLEMAN and D.C. YOUVAN

Genetic Coding Algorithms for Engineering Membrane Proteins

M. HUBER, E.J. LOUS, R.A. ISAACSON, G. FEHER, D. GAUL

and C.C. SCHENCK

EPR and ENDOR Studies of the Oxidized Donor in Reaction Centers

of Rhodobacter sphaeroides Strain R-26 and two Heterodimer

Mutants in which Histidine M202 or L173 was Replaced by Leucine

C.C. SCHENCK, D. GAUL, M. STEFFEN, S.G. BOXER, L. MCDOWELL,

C. KIRMAIER and D. HOLTEN

Site-Directed Mutations Affecting Primary Photochemistry in

Reaction Centers: Effects of Dissymmetry in the Special Pair

W.W. PARSON, V. NAGARAJAN, D. GAUL, C.C. SCHENCK,

Z.-T. CHU and A. WARSHEL

Electrostatic Effects on the Speed and Directionality of Electron

Transfer in Bacterial Reaction Centers: The Special Role

of Tyrosine M-208

K.A. GRAY, J.W. FARCHAUS, J. WACHTVEITL, J. BRETON,

U. FINKELE, C. LAUTERWASSER, W. ZINTH and D. OESTERHELT

The Role of Tyrosine M210 in the Initial Charge Separation in the

Reaction Center of Rhodobacter sphaeroides

H.U. STILZ, U. FINKELE, W. HOLZAPFEL, C. LAUTERWASSER,

W. ZINTH and D. OESTERHELT

Site-Directed Mutagenesis of Threonine M222 and Tryptophan M252

in the Photosynthetic Reaction Center of Rhodobacter sphaeroides

W.J. COLEMAN, E.J. BYLINA, W. AUMEIER, J. SIEGL, U. EBERL,

R. HECKMANN, A. OGRODNIK, M.E. MICHEL-BEYERLE and D.C. YOUVAN

Influence of Mutagenic Replacement of Tryptophan M250 on

Electron Transfer Rates Involving Primary Quinone in

Reaction Centers of Rhodobacter capsulatus

S.J. ROBLES, J. BRETON and D.C. YOUVAN

Transmembrane Helix Exchanges Between Quasi-Symmetric Subunits

of the Photosynthetic Reaction Center

J. BRETON, J.-L. MARTIN, J.-C. LAMBRY, S.J. ROBLES and D.C. YOUVAN

Ground State and Femtosecond Transient Absorption Spectroscopy

of a Mutant of Rhodobacter capsulatus which Lacks the

Initial Electron Acceptor Bacteriopheophytin 
N.W. WOODBURY, A.K. TAGUCHI, J.W. STOCKER

and S.G. BOXER

Preliminary Characterization of pAT-3, a Symmetry Enhanced

Reaction Center Mutant of Rhodobacter capsulatus . . . . . . . . . . . . . 303

A. STRUCK, D. BEESE, E. CMIEL, M. FISCHER, A. MÜLLER,

W. SCHÄFER and H. SCHEER

Modified Bacterial Reaction Centers: 3. Chemically

Modified Chromophores at Sites $\mathrm{B}_{\mathbf{A}}, \mathrm{B}_{\mathrm{B}}$ and $\mathrm{H}_{\mathrm{A}}, \mathrm{H}_{\mathrm{B}} \ldots \ldots \ldots \ldots \ldots$

K. WARNCKE and P.L. DUTTON

Effect of Cofactor Structure on Control of Electron Transfer

Rates at the $\mathrm{Q}_{\mathrm{A}}$ Site of the Reaction Center Protein . . . . . . . . . . . 327

PART IV Reaction Centers: Modelling of Structure/Function-Relationship

A. FREIBERG and T. PULLERITS

Energy Transfer and Trapping in Spectrally Disordered

Photosynthetic Membranes

M.R. WASIELEWSKI, G.L. GAINES, III, M.P. O’NEIL, W.A. SVEC,

M.P. NIEMCZYK and D. M. TIEDE

Multi-Step Electron Transfer in Rigid Photosynthetic

Models at Low Temperature: Requirements for Charge

Separation and Spin-Polarized Radical Ion Pair Formation . . . . . . . . . . . . . 349

P.O.J. SCHERER, W. THALLINGER and S.F. FISCHER

Electronic Couplings for Light Induced Charge Transfer

in Covalently Bonded Donor-Acceptor Systems . . . . . . . . . . . . . . . 359

J. FAJER, K.M. BARKIGIA, K.M. SMITH, E. ZHONG,

E. GUDOWSKA-NOWAK and M.D. NEWTON

Micro-Environmental Effects on Photosynthetic Chromophores . . . . . . . . . 367

A. SCHERZ, J.R.E. FISHER and P. BRAUN

Simulation of the Absorption and Circular Dichroism Spectra

for the Primary Electron Donor in Reaction Centers of

Purple Bacteria and Photosystem II

M. BIXON, J. JORTNER and M.E. MICHEL-BEYERLE

On the Primary Charge Separation in Bacterial Photosynthesis . . . . . . . . 389

P.O.J. SCHERER

Multiple Excited States of Photosynthetic Reaction Centers . . . . . . . . . 401

J. VRIEZE and A.J. HOFF

Exciton Band Mixing in Rhodopseudomonas viridis . . . . . . . . . . . . 409 
A.L. MORRIS, J.R. NORRIS and M.C. THURNAUER

An Extended Model for Electron Spin Polarization in Photosynthetic

Bacteria

E.W. KNAPP and L. NILSSON

Can Electron Transfer be Influenced by Protein Dynamics:

The Transfer from Cytochrome C to the Special Pair in

Photosynthetic Reaction Centers

\section{Concluding Remarks}

M.E. MICHEL-BEYERLE and H. SCHEER

Beyond Native Reaction Centers 453

Subject Index 464 



\title{
The Role of Tyrosine M210 in the Initial Charge Separation in the Reaction Center of Rhodobacter sphaeroides
}

\author{
K. A. Gray', J.W. Farchaus ${ }^{*}$, J.Wachtveitl', J. Breton², U. Finkele ${ }^{3}$, \\ C. Lauterwasser ${ }^{3}$, W. Zinth ${ }^{3}$, and D. Oesterhelt ${ }^{1}$ \\ I Max-Planck-Institut für Biochemie, W 8033 Martinsried, FRG \\ 2 Service de Biophysique, Département de Biologie, CEN Saclay, \\ 91191 Gif-sur-Yvette Cedex, France \\ 3 Physik-Department der Technischen Universität, W 8000 München 2, FRG \\ - Present address: Central Research and Development Dept., \\ E.I. DuPont de Nemours Co., Experimental Station, \\ P.O. Box 80173, Wilmington, DE. 19880, USA
}

\section{Abstract}

Site-directed mutants of tyrosine M210 (YM210) in the reaction center (RC) of Rhodobacter sphaeroides have been constructed and characterized to determine the effect of the changes on both the structure of the RC and its electron transfer kinetics. YM210 has been replaced by phenylalanine (FM210) and leucine (LM210). Both mutants are able to grow photosynthetically under high light but under low light the LM210 mutant is photosynthetic minus. Both mutant strains contain equal amounts of photobleachable RC in the intracytoplasmic membrane (normalized to total bacteriochlorophyll) as compared to wild type. Photobleaching spectra of mutant membranes are basically indistinguishable from wild type. Absorption spectra of purified mutant RCs also are basically the same as the wild type with small changes observed in the position and intensity of the $Q_{y}$ transition of the monomer bacteriochlorophylls. Picosecond kinetic analysis shows that both the lifetime of the excited state of the primary electron donor $\left(\mathrm{P}^{*}\right)$ and the rise time of the first reduction step are longer in both mutants. These processes occur in $3.5 \mathrm{ps}$ in the wild type $\mathrm{RC}$ while the corresponding time constants in the mutants are $16 \pm 6$ ps in FM210 and $22 \pm 8$ ps in LM210.

\section{Introduction}

Electron transfer within the bacterial photosynthetic reaction center (RC) has been shown by a variety of methods to only occur along one branch of the chromophores (the so-called $\mathrm{L}$ or A branch) (Kirmaier and Holten, 1987; Parson, 1987). Recent room temperature kinetic data support a model in which the electronically excited primary donor (a dimer of bacteriochlorophylls, P) decays with a time constant of 3.5 ps (in Rhodobacter (Rb.) sphaeroides) to populate a very short-lived intermediate containing $\mathrm{P}+$ and a reduced bacteriochlorophyll (B') molecule (Holzapfel et al., 1989, 1990). Subsequently the electron is transferred to a bacteriopheophytin $(\mathrm{H})$ with a time constant of $0.9 \mathrm{ps}$. The existence of the state $\mathrm{P}^{+} \mathrm{H}^{-}$is generally accepted but there is presently debate over the existence of the 
intermediate $\mathrm{P}^{+} \mathrm{B}-$. Measurements performed at 10K (Fleming et al., 1988; Breton et al., 1988 ) and with RC from the bacterium Rb. capsulatus (Kirmaier and Holten, 1988) have not detected a distinct radical pair before $\mathrm{P}^{+} \mathrm{H}^{-}$.

When one inspects the positions of the chromophores in the X-ray structure the basis for the unidirectionality of electron transfer is not obvious. The chromophores are arranged with a two fold rotational symmetry resulting in two equivalent branches (reviewed in Deisenhofer and Michel, 1989; Chang et al., 1986; Tiede et al., 1988; Rees et al., 1989). If one, though, considers the protein environment surrounding the prosthetic groups it is possible to observe residues that break the apparent $\mathrm{C}_{2}$ symmetry. Tyrosine M210 (YM210) is one of these residues. YM210 is in the binding pockets of $\mathrm{P}$ and the monomer bacteriochlorophyll on the L-side $\left(B_{L}\right)$ (Fig. 1). It appears to be in Van der Waals contact with $P$ but is not close enough to hydrogen bond. The corresponding residue on the symmetry-related $\mathrm{M}$-side is a phenylalanine, FL181. It has been suggested (Allen et al., 1988) that YM210 may act as a conduit for electrons as they are transferred from the excited state special pair to the bacteriopheophytin on the active branch $\left(\mathrm{H}_{\mathrm{L}}\right)$. Both YM210 and FL181 are conserved in several species of photosynthetic bacteria, namely Rhodopseudomonas (Rps.) viridis, $R b$. sphaeroides, Rb. capsulatus and Rhodospirillum rubrum (Williams et al., 1986; Komiya et al., 1988). In the green bacterium Chloroflexus (C.) aurantiacus a leucine occupies the position at M210 (Ovchinikov et al., 1988a, b; Shiozawa et al., 1989) and initial charge separation has been shown to be slower than in Rb. sphaeroides ( $7-10$ ps vs. $3.5 \mathrm{ps)}$ (Kirmaier et al., 1983, 1986; Becker et al., 1989). Recent calculations from Parson and coworkers (Parson et al., 1990) have suggested that the electrostatic interactions of YM210 with $\mathrm{B}_{\mathrm{L}}$ may decrease the energy level of the state $\mathrm{P}^{+} \mathrm{B}_{\mathrm{L}}$ - below that of $\mathrm{P}^{*}$ so as to facilitate electron transfer along the active branch. The insertion of another residue in this position may alter the energy level of $\mathrm{P}^{+} \mathrm{B}_{\mathrm{L}}{ }^{-}$thereby influencing the rate and energetics of electron transfer from $\mathrm{P}^{*}$.

We have used site-directed mutagenesis in combination with picosecond absorption spectroscopy to probe the role of YM210 in the initial charge separation in the reaction center of $R b$. sphaeroides. Tyrosine has been replaced by phenylalanine and leucine. The exchange to phenylalanine makes the structure more symmetric and at the same time removes the polarity caused by the hydroxyl group while retaining the aromatic ring. The exchange to leucine was used to investigate the influence of the conjugated pi electron system. We have tried to separate effects caused by any secondary structural perturbations upon mutation from the effects due mainly to the removal of either the hydroxyl or the aromatic group. Results from the following experiments are consistent with the calculations performed by Parson et al. (1990), that is, we show that the lifetime of the excited state, $\mathrm{P}^{*}$, is indeed longer in both the $\mathrm{F}$ and $\mathrm{L}$ mutants. Additionally it was determined that the formation of the first charge transfer state occurs with a slower time constant in both mutants compared to the wild type. We 


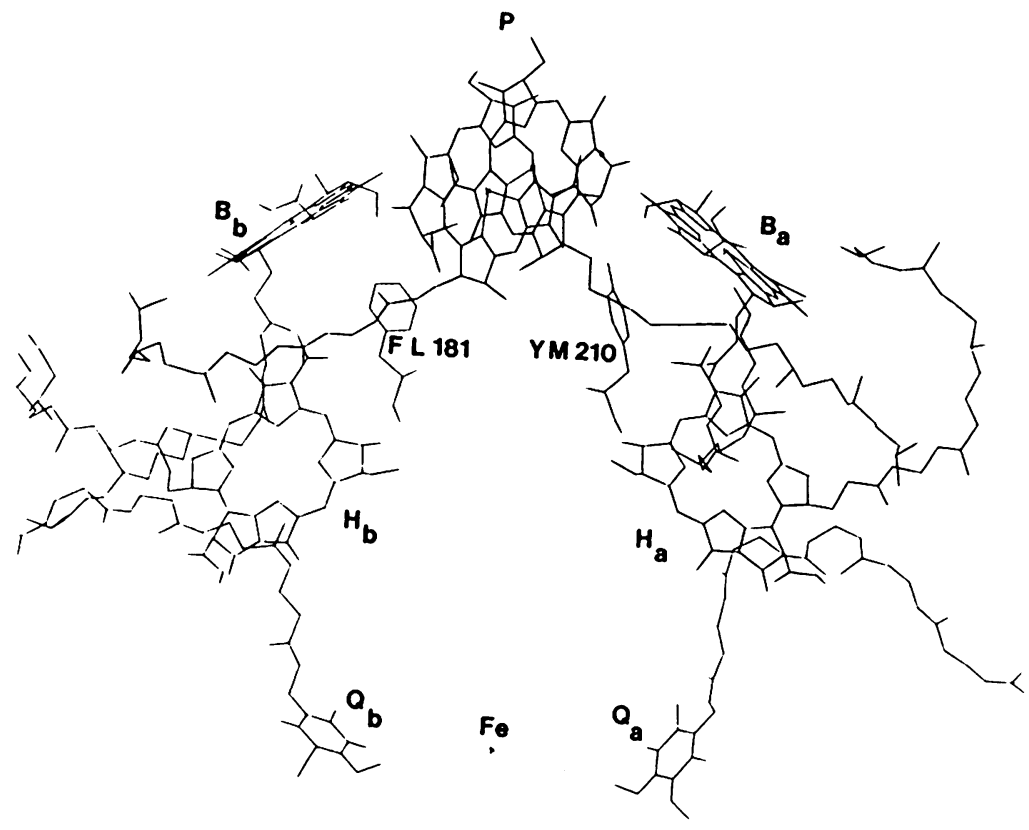

Fig. 1. Chromophores of the RC from $R b$. sphaeroides showing YM210 and FL181. P is the dimer of bacteriochlorophylls, $\mathrm{B}_{\mathrm{a}}$ and $\mathrm{B}_{\mathrm{b}}$ the monomer bacteriochlorophylls, $\mathrm{H}_{\mathrm{a}}$ and $\mathrm{H}_{\mathrm{b}}$ the monomer bacteriopheophytins, $\mathrm{Q}_{\mathrm{a}}$ and $\mathrm{Q}_{\mathrm{b}}$ the quinones and $\mathrm{Fe}$ the non-heme iron. The coordinates were kindly provided by Drs. M. Schiffer and J. Norris of Argonne National Laboratories, Argonne, Il. USA.

conclude that the influence of the hydroxyl group is greater than that of the aromatic ring based on the different time constants observed between the mutants.

\section{Materials and Methods}

Site-directed mutagenesis was performed using the gapped duplex method as described by Stannsens et al. (1989). A $3.8 \mathrm{~kb}$ Bam HI - HindIII fragment containing the puf L and M genes (Farchaus et al., 1990a, b) was cloned into pMa/c (designated pMa3.8 and pMc3.8). This construct (pMa3.8) was digested with the restriction enzymes $N r u$ I and XhoI to produce a 369 bp gap which encompassed the region to be mutagenized (Gray et al., 1990). Synthetic oligonucleotides (21-mers) containing mismatches at the codon for M210 (TAC, TTC, CTG for Y, F and L respectively) were annealed to the gapped duplex and filled-in in vitro with the four dNTPs, Klenow fragment and T4 ligase. The filled-in mixture was used to transform the E. coli strain WK6mutLrecAsup-. Transformants containing the mutations were initially selected by colony hybridization using the mutagenic oligonucleotide labelled with $32 \mathrm{p}$. Single strand plasmid DNA was isolated from the positive clones and the 369 bp gap was sequenced using Sequenase (US Biochemicals). The mutagenized $3.8 \mathrm{~kb}$ fragments were subcloned into the broad host range plasmid pRK404 along with the $1.5 \mathrm{~kb}$ fragment 
containing the puf X gene (it has been shown by Farchaus et al. (1990b), that the pufX gene is necessary for competent photosynthetic growth) and subsequently used to transform $E$. coli S17-1. Conjugation into the $R b$. sphaeroides PUF $\triangle \mathrm{LMX}$ deletion strain was performed by the diparental filter mating procedure as described previously (Davis et al., 1988).

Exconjugants were selected on plates containing kanamycin $(25 \mu \mathrm{g} / \mathrm{ml})$ and tetracyclin $(2$ $\mu \mathrm{g} / \mathrm{ml}$ ) (the PUF $\triangle \mathrm{LMX}$ deletion strain contains a kanamycin resitance gene [Farchaus and Oesterhelt, 1989] while pRK404 has a tetracyclin resistance gene). Photoheterotrophic growth was tested on plate in anaerobic light chambers as described in Farchaus and Oesterhelt (1989).

The $R b$. sphaeroides deletion strains complemented in trans with either the wild type puf operon or the mutated puf operons were grown semi-aerobically in Sistrom's minimal medium (supplemented with $25 \mu \mathrm{g} / \mathrm{ml}$ kanamycin and $2 \mu \mathrm{g} / \mathrm{ml}$ tetracyclin) with a final $\mathrm{pO}_{2}$ of less than $5 \mathrm{mmHg}$. Reaction center was isolated from the respective mutant and wild type strains by extraction of the chromatophores with the detergent $\mathrm{N}, \mathrm{N}$-dimethyldodecylamine- $\mathrm{N}$-oxide (LDAO) and purification over anion exchange columns (Ogrodnik et al., 1987; Gray et al., 1990). Purity was defined by the ratio of the absorption at $280 \mathrm{~nm}$ to that at $803 \mathrm{~nm}$. These ratios were typically 1.2. When necessary LDAO was exchanged with n-octyl-B-Dglucopyranoside (OG).

Subsaturating photobleaching spectra were taken on chromatophores as described previously (Farchaus et al., 1990a). Room temperature absorption spectra were taken on a Shimadzu UV-160 spectrophotometer or an Aminco DW2a spectrophotometer. Low temperature absorption and linear dichroism (LD) spectra (10K) were taken on a previously described apparatus (Breton, 1985) of RCs immobilized in polyacrylamide gels and squeezed uniaxially (Breton, 1988).

Picosecond kinetic measurements were performed at $298 \mathrm{~K}$ using the apparatus and methods described in Holzapfel et al. $(1989,1990)$. An $860 \mathrm{~nm}$ excitation pulse ( $\left.\mathrm{t}_{\mathrm{p}} \leq 100 \mathrm{fs}\right)$ was used to excite $\mathrm{P}$ in its lowest energy transition. The excitation intensity was adjusted so that less than $12 \%$ of the RC in the irradiated volume were excited. The subsequent population of different intermediates leads to characteristic time-dependent changes of the absorption spectrum. These absorption changes were monitored by properly delayed probing pulses $\left(t_{p} \leq 150 \mathrm{fs}\right)$ of very low intensity and accurately measured by a sensitive difference detection system. At a probing wavelength of $920 \mathrm{~nm}$ (stimulated emission of the singlet excited state $\mathrm{P}^{*}$ ) a parallel polarization of exciting and probing pulses was used; at a probing wavelength of $665 \mathrm{~nm}$ (absorption of a BChl and Bphe anion) both parallel and perpendicular polarizations were used. The transient absorbance data are plotted as a function of delay time on a linear scale for $t_{D}<1$ ps and on a logarithmic scale for delay times greater than $1 \mathrm{ps}$. 


\section{Results}

Photosynthetic Growth. Both the FM210 and the LM210 mutants were capable of photosynthetic growth under high light conditions $\left(80 \mathrm{~W} / \mathrm{m}^{2}\right)$ on plate. Under low light conditions $\left(20 \mathrm{~W} / \mathrm{m}^{2}\right)$ though it was shown that the LM210 mutants were incapable of photosynthetic growth and had a reversion frequency of $10^{-4}-10^{-5}$.

Spectroscopy. After excitation by a photon distinct changes occur in the absorption spectrum of the RC. In particular the singlet excited state $\mathrm{P}^{*}$ and the cation $\mathrm{P}+$ do not absorb at $865 \mathrm{~nm}$ as does the neutral ground state. Additionally the absorption spectrum of the monomer Bchls are perturbed due to the electric field produced by the radical pair $\mathrm{P}^{+} \mathrm{Q}_{\mathrm{A}}$ These changes result in a distinctive light minus dark difference spectrum. Fig 2 shows subsaturating light minus dark difference spectra for wild type chromatophores (Fig. 2a); FM210 chromatophores (Fig. 2b), and; LM210 chromatophores (Fig. 2c). These spectra show that $\mathrm{RC}$ is present and functional in both mutants. The general pattern of the difference spectra are essentially the same with a maximum bleaching at $865 \mathrm{~nm}$ and a derivative-like feature centered around $800 \mathrm{~nm}$ due to the electrochromic shift of the monomer Bchls. There are however some subtle differences between the mutants and the wild type. For instance the isosbestic point of the electrochromic shift is at $798 \mathrm{~nm}$ in the wild type and $801 \mathrm{~nm}$ in both mutants. The ratio of the maximum bleaching at $865 \mathrm{~nm}$ to the feature at $810 \mathrm{~nm}$ was consistently 2 in the wild type whereas this ratio was consistently 1.55 in both mutants. Saturating photobleaching experiments (data not shown) showed equal signals at $865 \mathrm{~nm}$ for the mutants and the wild type (the amount of membranes were normalized to Bchl concentration) which would suggest that there is no difference in the amount of RC inserted in the intracytoplasmic membrane (ICM) as well as suggesting that the differences observed in the ratios mentioned above are not attributable to $\mathrm{P}$ but to the monomer Bchls.

The low temperature absorption and LD spectra of the purified RCs (Fig. 3) showed basically no difference between wild type and mutants. One does observe, though, a detergent dependent blue shift in the long wavelength $\mathrm{Q}_{\mathrm{y}}$ absorption band at room temperature (from $865 \mathrm{~nm}$ to $858-860 \mathrm{~nm}$ ) of the mutant RCs. This shift was shown to be detergent dependent, hence a consequence of the extraction from the membrane, since detergent exchange to octylglucoside resulted in a return of this band to about $865 \mathrm{~nm}$. At low temperature though the long wavelength band of $P$ is actually shifted to the red in both mutants compared to wild type. Additional evidence supporting the premise that this shift was due to a secondary effect was that the photobleaching spectra of the chromatophores showed no shift in the position of the maximum (865 $\mathrm{nm}$ ) of the $\mathrm{P}$ band. The $\mathrm{Q}_{\mathrm{y}}$ transition of the monomer Bchls was shifted $3 \mathrm{~nm}$ to the red (from $803 \mathrm{~nm}$ in the wild type to $806 \mathrm{~nm}$ in the mutants).This shift was not detergent-dependent and may be related to the $3 \mathrm{~nm}$ red shift of the isosbestic point observed in the photobleaching spectra. The intensity of the $\mathrm{Q}_{\mathrm{y}}$ band of the monomer Bchls also appeared to increase. After pigment extraction and pheophytinization 


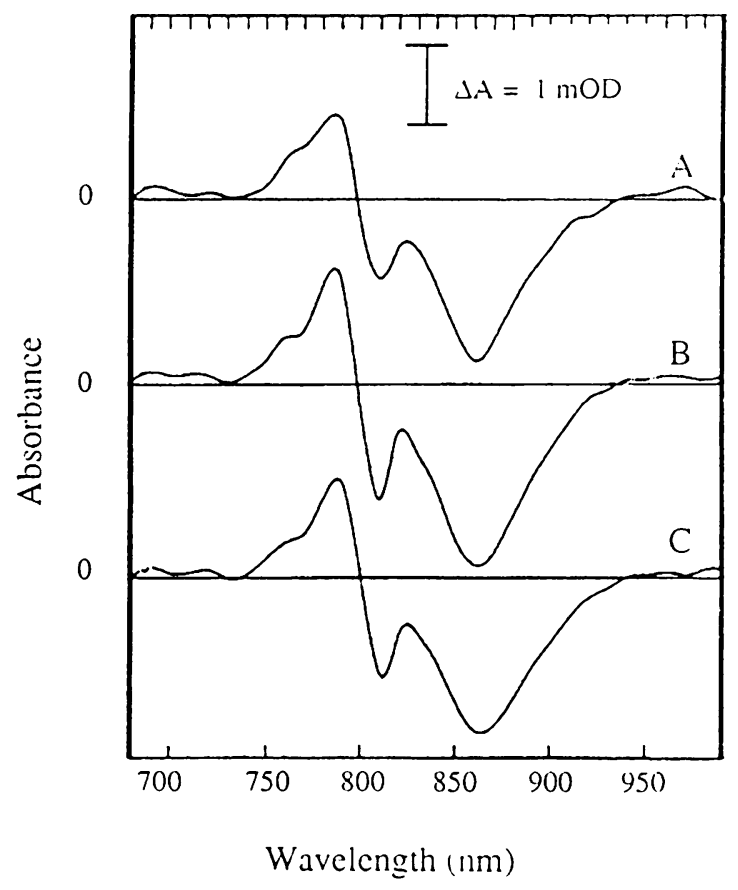

Fig 2. Sub-saturating photobleaching spectra of purified chromatophores isolated from A) Wild type cells, B) FM210 cells and C) LM210 cells. All three were grown semi-aerobically. The chromatophores were suspended in $50 \mathrm{mM}$ MOPS, $100 \mathrm{mM} \mathrm{KCl}$ containing $9 \mu \mathrm{M}$ valinomycin and $1 \mathrm{mM}$ ascorbate.

(Straley et al., 1973) a new extinction coefficient was calculated for the mutant RCs. This extinction coefficient was $322 \pm 15 \mathrm{mM}^{-1} \mathrm{~cm}^{-1}$ (at $806 \mathrm{~nm}$ ) as compared to $288 \pm 14 \mathrm{mM}^{-1}$ $\mathrm{cm}^{-1}$ (at $803 \mathrm{~nm}$ ) in the wild type (Straley et al., 1973). There also appears to be small absorption maxima shifts in the $Q_{x}$ peak of $H_{M}$ (535 nm in wild type).

The LD spectra (Fig. 3) of the three RCs are essentially the same. There are no changes in the angles of the transition moments of $\mathrm{P}$, the monomer Bchls and the Bphe molecules beyond the limits of accuracy of the technique $\left( \pm 5^{\circ}\right)$. Within the limits, though, there is an indication that the angle between the $C_{2}$ axis and the $Q_{y}$ transition of the Bphe molecules might be somewhat smaller for the mutants.

Initial electron transfer kinetics. Fig 4 shows the kinetics of the decay of the singlet excited state $P^{*}$ after excitation by a short duration ( $\leq 100 \mathrm{fs}$ ) actinic laser flash. At a probing wavelength of $920 \mathrm{~nm}$ one observes stimulated emission from $\mathrm{P}^{*}$ and the decay of this signal corresponds to the lifetime of the excited state. As can be seen in Fig 4 (top panel) P* decays monoexponentially with a time constant of $3.5 \pm 0.4 \mathrm{ps}$ in wild type RC. Fig 4 (middle) and 4 (bottom) correspond to the data obtained using RC isolated from the FM210 and LM210 mutants, respectively. It is immediately apparent that the lifetime of the excited state in these $\mathrm{RCs}$ is much longer. The data from the FM210 RC are fit with a $16 \pm 6 \mathrm{ps}$ time constant 


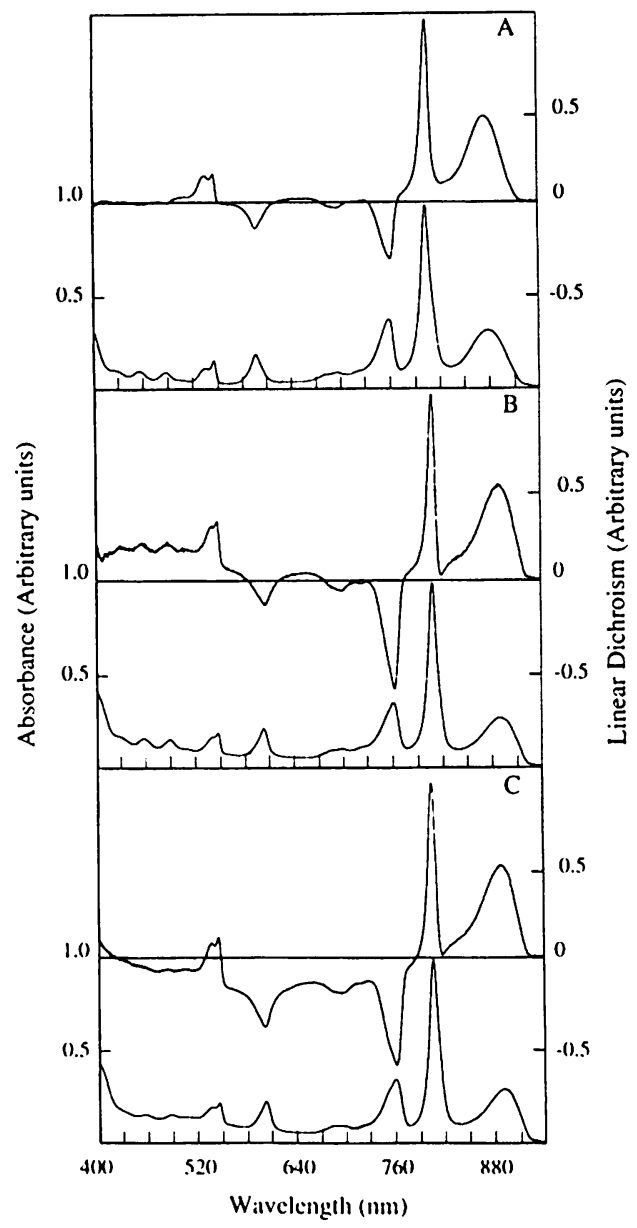

Fig. 3. Low temperature (10K) absorption and linear dichroism spectra of A) wild type, B) FM210 and C) LM210 RCs polymerized in polyacrylamide gels and squeezed uniaxially. while the data from the LM $210 \mathrm{RC}$ are fit with a $22 \pm 8$ ps time constant. Additionally it is no longer possible to fit the data satisfactorily with a single exponential; a second longer time constant must be used for both sets of data (70 ps for FM210 and 90 ps for LM210). For both mutant RCs the amplitude of the faster component is approximately three times larger than that of the slower one. At $665 \mathrm{~nm}$ the neutral ground state RC does not absorb appreciably but at this wavelength one can monitor a Bchl or Bphe anion. Fig. 5 (top) shows the kinetics of the signal at $665 \mathrm{~nm}$ after excitation of wild type RC. One observes a rise time corresponding to a time constant of $3.5 \mathrm{ps}$ and a subsequent decay time corresponding to a time constant of $220 \mathrm{ps}$. For perpendicular polarization the rise time is mainly due to the 
formation of $\mathrm{H}_{\mathrm{L}}{ }^{-}$while the decay time is associated with the transfer of an electron from $\mathrm{H}_{\mathrm{L}}{ }^{-}$ to $\mathrm{Q}_{\mathrm{A}}$. For parallel polarization and wild type samples a $0.9 \mathrm{ps}$ component is observed and was interpreted as electron transfer from $B_{L}$ to $H_{L}$ (Holzapfel et al., 1990). The data shown in Fig 5 (middle) and 5 (bottom) were taken from measurements on FM210 and LM210 RC, respectively (perpendicular polarization). Once again it is immediately apparent that the first reduction process takes place much slower in both mutants. The fits correspond to time constants of 16 ps (FM210) and 22 ps (LM210). These time constants parallel the decay of

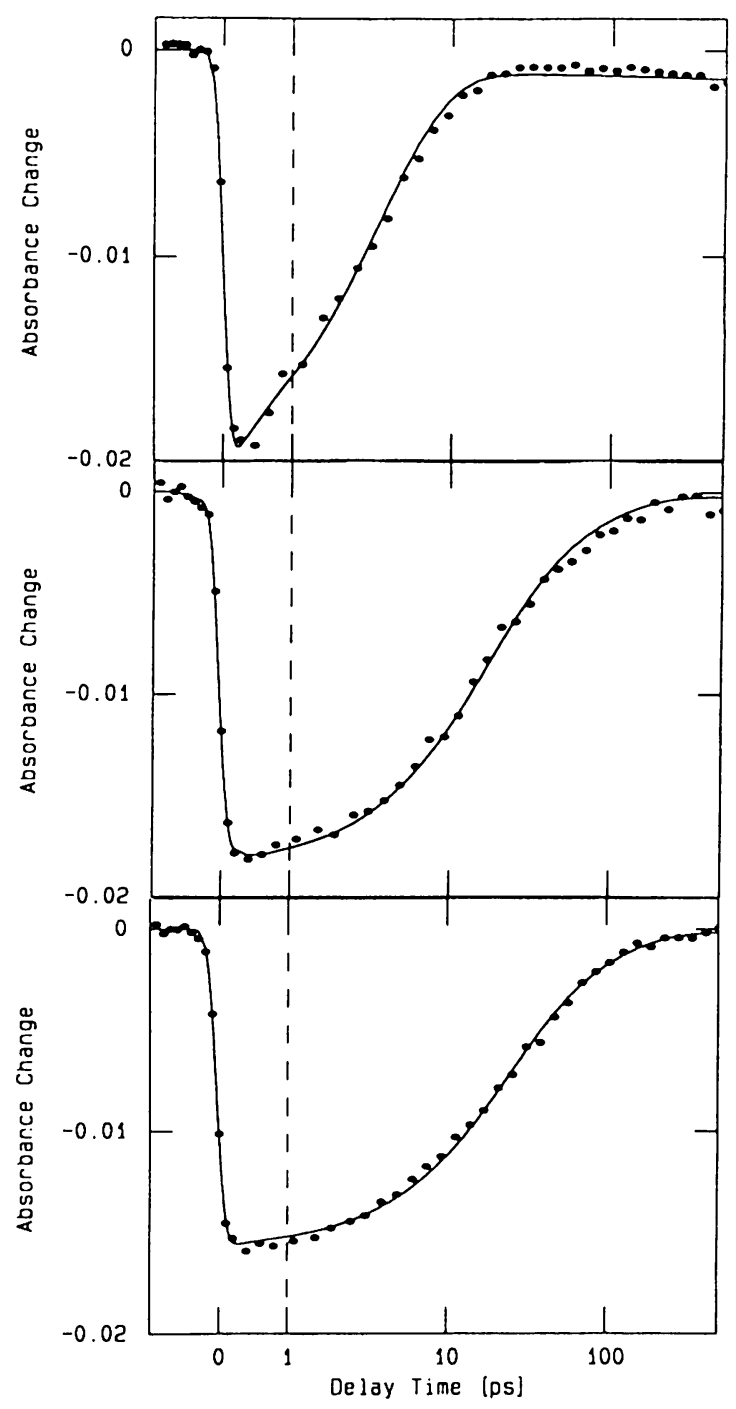

Fig. 4. Transient absorption data measured at $920 \mathrm{~nm}$ for the wildtype (top), FM210 (middle) and LM210 (bottom) RC. The solid curves are calculated using a rate equation system while the time constants are given in the text. 


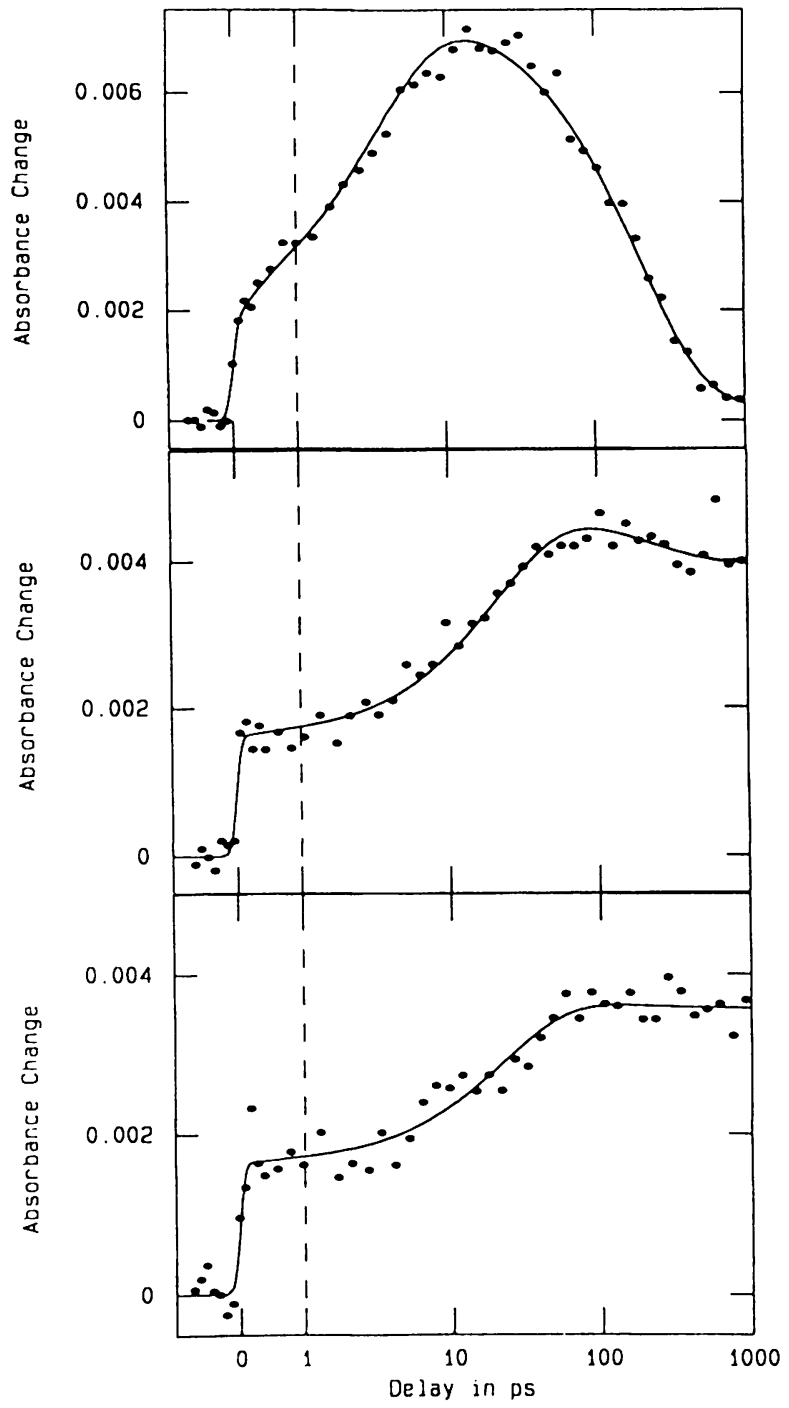

Fig. 5. Transient absorption data measured at $665 \mathrm{~nm}$ using perpendicular polarized pulses for wildtype(top), FM210 (middle) and LM210 (bottom) RC.

the excited state as seen in Fig. $4(920 \mathrm{~nm})$. When parallel polarization was used with mutant samples (data not shown) no 0.9 ps process was observed. This may be explained by the fact that when the 3.5 ps process is slowed to approximately 20 ps the 0.9 ps component would not be observed due to the signal to noise. At longer times the pattern deviates from the wild type. The decay of the $665 \mathrm{~nm}$ signal of FM210 can be fit with a 220 ps time constant but with a much smaller amplitude and it does not recover to the baseline completely. There is no detectable 200 ps component in the LM210 sample. The reason for these deviations is that both RC preparations contained very little quinone at the $\mathrm{Q}_{\mathrm{A}}$ site (Gray et al., 1990), that is there is no acceptor for the electron from $\mathrm{H}_{\mathrm{L}}$. From the present data at $665 \mathrm{~nm}$ we can not 
deduce unambiguously the need of a longer (70 - $90 \mathrm{ps)} \mathrm{time} \mathrm{constant} \mathrm{as} \mathrm{seen} \mathrm{in} \mathrm{the} 920 \mathrm{~nm}$ data of the mutant RCs.

\section{Discussion}

The experiments presented above show that YM210 indeed plays a role in the initial electron transfer dynamics that take place in the reaction center of $R b$. sphaeroides. The mutation does not seem to affect the expression of the $\mathrm{RC}$ or the folding and the insertion into the membrane. Normalization of membrane preparations to Bchl concentration indicated equal amounts of photobleachable RC in the ICM. Subsaturating photobleaching spectra of membrane particles as well as absorption spectra (room temperature and liquid helium temperature) indicate that the absorption properties of the monomer Bchl(s) appear to be affected. Both an increase in intensity and a shift in the absorption maximum of the the $Q_{y}$ band attributed to the monomer Bchls occur after the repalcement of YM210 with F or L. Previous photochemical trapping experiments have been used to show that $\mathrm{B}_{\mathrm{L}}$ absorbs at a shorter wavelength $(803 \mathrm{~nm})$ than $\mathrm{B}_{\mathrm{M}}(806 \mathrm{~nm})$ (Robert et al., 1985). The insertion of phenylalanine or leucine at M210 appears to shift the absorption peak of $B_{L}$ from $803 \mathrm{~nm}$ to $806 \mathrm{~nm}$, similar to that of $\mathrm{B}_{\mathrm{M}}$. This could be a consequence of the environment around $\mathrm{B}_{\mathrm{L}}$ becoming less polar. We can not rule out though that the hydroxyl group is hydrogen bonded to a water (or some other group in the area) and then interacts directly with either $\mathrm{P}$ or $\mathrm{B}_{\mathrm{L}}$ and subsequently affects the absorption properties of $\mathrm{B}_{\mathrm{L}}$. Interestingly, as stated above, a phenylalanine ( 181 ) occupies the symmetry related position on the $M$ side of the $R C$ which may be a reason for the lower energy transition of $B_{M}$.

We have shown using low temperature linear dichroism spectroscopy on isolated RCs that there is no large scale re-orientation of the chromophores that may be caused by the mutagenesis. Additionally we have used resonance Raman spectroscopy (Mattioli et al., 1990) on isolated RCs to show that all of the interactions of the chromophores are unaltered both in the neutral state and the radical pair state $\mathrm{P}^{+} \mathrm{Q}_{\mathrm{A}}{ }^{-}$. Furthermore, the light-induced FTIR

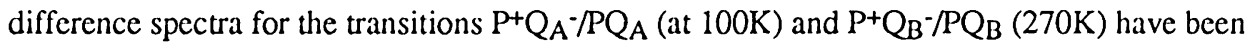
compared for purified chromatophores from YM210, FM210 and LM210 (J.B., K.A.G, D.O., W. Mäntele, E. Nabedryk, unpublished results). This approach is well suited to detect with very high sensitivity even minor alterations in the environment and/or bonding pattern of an amino acid residue in light-transducing systems (Mäntele $e t$ al, 1985). Even after extensive signal averaging (involving 30,000 to 100,000 interferograms, depending on the sample), no significant difference between the spectra for the wild type and the mutants could be detected. This observation is taken to indicate that (i) YM210 is not affected by charge separation in a way which alters its vibrational properties and (ii) any interaction which could exist between YM210 (or the residues by which it is replaced in FM210 and LM210) and P or the neighboring pigments is silent in the FTIR difference spectra. These experiments are necessary to exclude any secondary structural perturbations that may be large enough to affect 
the electron transfer kinetics. There do appear to be some structural perturbations, though, which are manifested in a loss of quinone at $\mathrm{Q}_{\mathrm{A}}$ during the isolation procedure. Both FM210 and LM210 RCs contain much less bound quinone after purification than does wild type RC (Gray et al., 1990). We were able to show that this loss of quinone occurs after detergent extraction and is not the case in the membrane. The loss of quinone may be explained in terms of the location of M210. M210 is on the same membrane spanning helix (D) that forms the binding pocket of $\mathrm{Q}_{\mathrm{A}}$ (Allen et al., 1988) and a slight destabilization of this helix may somehow be transmitted to the quinone binding site thus causing a loss of quinone during the isolation.

A compelling reason to study YM210 relies on evidence from other systems that tyrosines act as distinct electron acceptors/donors. For example in photosystem II of higher plants, tyrosines have been shown to be involved in mediating electron transfer from the $\mathrm{Mn}$ containing, oxygen evolving complex to P680 (Debus et al., 1988a, b). There is no evidence from bacterial RC that YM210 acts in a similar way between $\mathrm{P}$ and the primary acceptor but it may be important in optimizing the thermodynamic and/or kinetic properties of the intermediates in electron transfer. In fact, electrostatic interaction calculations (Parson et al., 1990) suggest YM210 partially determines the energy level of the state $P^{+} B_{L}$ - To test these ideas we have measured the picosecond reaction dynamics of YM210 mutants. Both the FM210 and LM210 RC show an increased lifetime for the excited state P*; 16 ps for FM210 and 22 ps for LM 210 as compared to $3.5 \mathrm{ps}$ in the wild type. The increased lifetime parallels the observation of the first reduction step. It may be argued that the loss of quinone at $\mathrm{Q}_{\mathrm{A}}$ is what is slowing down the electron transfer but other mutants in which similar amounts of quinone are lost show no deviation in the rate of initial electron transfer (Stilz et al., submitted). Similar mutants (F and I) constructed by another group (Schenck et al, 1989 and W. Parson, personal communication) have given time constants comparable (10.5 \pm 1 ps and $16 \pm 1 \mathrm{ps}$, respectively) to those reported here.

An important question to address is what properties of tyrosine are important in influencing the rate of electron transfer. The removal of the hydroxyl group, thus the loss of the dipole when $\mathrm{F}$ is inserted, results in an increased time constant for the lifetime of the excited state and the formation of the first radical pair by a factor of almost 5 compared to wild type. Upon removal of the aromatic group and replacement with an aliphatic ( $\mathrm{Y} \rightarrow \mathrm{L})$ the time constants are again increased but by only a relatively small amount. These results would tend to suggest that both the hydroxyl and the aromaticity influence the electron transfer but the hydroxyl group has more of an influence than the presence of a conjugated pi electron system. Indeed, if this is true a replacement of FL181 (the symmetry related residue on the inactive branch) with a tyrosine may affect the unidirectionality of electron transfer, that is one may begin to obscrve electron transfer to the M-side bacteriochlorins. These studies are currently underway. 
The replacement of tyrosine by either phenylalanine or leucine apparently does not affect the photosynthetic growth of the cells under high light. But under conditions where light is limiting the LM210 mutant is not capable of photosynthetic growth. A recent report by another group (Schenck, et al, 1989) indicates that they also see non-photosynthetic growth in a mutant in which an aliphatic side chain was inserted at M210 while a phenylalanine substitution, in their hands, is also photosynthetically competent. We have not yet tested the basis for this growth pattern but it may possibly be explained in terms of the lifetime of the excited state $\mathrm{P}^{*}$. As shown above the lifetime of $\mathrm{P}^{*}$ in both mutants is much longer than in the wild type. The $\mathrm{RC}$ receives excitation via the light harvesting complexes and the transfer of this excitation to the RC occurs in approximately 20-30 ps (van Grondelle et al., 1987; Bergström et al., 1989). Since the lifetime of $\mathrm{P}^{*}$ in wild type is short (3.5 ps) there is essentially no accumulation of $\mathrm{P}^{*}$ and energy transfer is efficient. If the lifetime of $\mathrm{P}^{*}$ is much longer then it is possible that some of the excitation from the LH complexes is lost via some non-productive relaxation process(es) or competing back reactions. Apparently under conditions of high light the excitation is not limiting thus both mutants are able to grow. But under conditions of lower light the excitation is limiting and the energy transfer to the RC may not be as efficient due to the longer lifetime of the excited state P*. Since the FM210 mutant is able to grow using $20 \mathrm{~W} / \mathrm{m}^{2}$ with apparently no difficulty, the $16 \pm 6$ ps lifetime of $\mathrm{P} *$ is still short enough with this intensity for efficient energy transfer whereas the $22 \pm 8$ ps lifetime measured in the LM $210 \mathrm{RC}$ is too long. The above argument is based on the presumption that the difference between the lifetimes in the two mutants is large enough to cause this effect. Alternately, the inability to grow under low light could be explained by a decrease in the photochemical quantum yield in the reaction center itself. Preliminary results (K. Gray, unpublished results) indicate that the quantum yield, $\Phi_{\mathrm{QA}}$, in the mutant RCs is still close to 1 therefore this explanation is not valid. Experiments are underway to determine if indeed there is a decreased efficiency of transfer of excitation from the light harvesting complexes to the $\mathrm{RC}$ in the LM210 mutant.

\section{References}

Allen, J.P., Feher, G., Yeates, T.O., Komiya, H. and Rees, D.C. (1988) In J. Breton and A. Vermeglio (eds.) The Photosynthetic Bacterial Reaction Center, Structure and Dynamics. Plenum Press, New York, pp.5 - 11.

Becker, M., Middendorf, D., Nagarajan, V., Parson, W.W. and Blankenship, R.E. (1989) Abstracts VIIIth International Congress on Photosynthesis. Physiologia Planatarum ,76, A32.

Bergström, H., van Grondelle, R. and Sunström, V. (1989) FEBS Lett., 250, 503 - 508.

Breton, J. (1985) Biochim. Biophys. Acta, 810, 235 - 245.

Breton, J. (1988) In J. Breton and A. Vermeglio (eds.) The Photosynthetic Bacterial Reaction Center, Structure and Dynamics. Plenum Press, New York, pp. 59 - 69.

Breton, J., Martin, J.L., Fleming, G.R. and Lambry, J.C. (1988) Biochem., 27, 8276 8284.

Chang, C.H., Tiede, D.M, Tang, J., Smith, U., Norris, J. and Schiffer, M. (1986) FEBS Lett., 205, 82 - 86.

Davis, J., Donohue, T.J. and Kaplan, S. (1988) J. Bacteriol. 170, 320 - 329. 
Debus, R.J., Barry, B.A., Sithole, I., Babcock, G.T. and McIntosh, L. (1988a) Proc. Natl. Acad. Sci. USA, 85, 427 - 430.

Debus, R.J., Barry, B.A., Sithole, I., Babcock, G.T. and McIntosh, L. (1988b) Biochem., 27, 9071 - 9074.

Deisenhofer, J. and Michel, H. (1989) EMBO J., 8, 2149 - 2170.

Farchaus, J.W. and Oesterhelt, D. (1989) EMBO J., 8, 47 - 54.

Farchaus, J.W., Gruenberg, H., Gray, K.A., Wachtveitl, J., DeHoff, B., Kaplan, S. and Oesterhelt, D. (1990a) In G. Drews (ed.) Molecular Biology of Membrane-Bound Complexes in Photosynthetic Bacteria. Plenum Press, London.

Farchaus, J.W., Gruenberg, H. and Oesterhelt, D. (1990b) J. Bacteriol., 172, 977 - 985

Fleming, G.R., Martin, J.L. and Breton, J. (1988) Nature ,333, 190 - 192.

Gray, K.A., Farchaus, J.W., Wachtveitl, J., Breton, J. and Oesterhelt, D. (1990) EMBO J. 9, $2061-2070$.

Holzapfel, W., Finkele, U., Kaiser, W., Oesterhelt, D., Scheer, H., Stilz, H.U. and Zinth, W. (1989) Chem. Phys. Lett., 60, 1 - 7.

Holzapfel, W., Finkele, U., Kaiser, W., Oesterhelt, D., Scheer, H., Stilz, H.U. and Zinth, W. (1990) Proc. Natl. Acad. Sci. USA, 87, 5168 - 5172.

Kirmaier, C., Holten, Blankenship, R.E. (1986) Biochim. Biophys. Acta , 850, 275 - 285.

Kirmaier, C. and Holten, D. (1987) Photosyn. Res., 13, $225-260$.

Kirmaier, C. and Holten, D. (1988) FEBS Lett., 239, 211 - 218.

Kirmaier, C., Holten, D., Feick, R., Blankenship, R.E. (1983) FEBS Lett., 158, 73 - 78.

Komiya, H., Yeates, T.O., Rees, D.C., Allen, J.P. and Feher, G. (1988) Proc. Natl. Acad. Sci. USA, 85, 9012 - 9016.

Mäntele, W., Nabedryk, E., Tavitian, B.A., Kreutz, W. and Breton, J. (1985) FEBS Lett., $187,227-232$.

Mattioli, T.A., Gray, K.A., Lutz, M., Oesterhelt, D. and Robert, B. (1990) Biochem. (in press).

Ogrodnik, A., Volk, M., Letterer, R., Feick, R. and Michel-Beyerle, M.E. (1988) Biochim. Biophys. Acta 936, 361 - 371.

Ovchinnikov, Y. A., Abdulaev, N. G., Shmuckler, B. E., Zargarov, A. A., Kutuzov, M. A., Telezhinskaya, I. N., Levina, N. B.and Zolotarev, A. S. (1988a) FEBS Lett. 232, 364 368.

Ovchinnikov, Y. A., Abdulaev, N. G., Zolotarev, A. S., Shmukler, B. E., Zargarov, A. A., Kutuzov, M. A., Telezhinskaya, I. N. and Levina, N. B. (1988b) FEBS Lett. 231, 237 242.

Parson, W. W. (1987) In J. Amezs (ed.) Photosynthesis. Elsivier Science Publishers BV, Amsterdam, pp. 43 - 61.

Parson, W.W. and Case, G.D. (1970) Biochim. Biophys. Acta, 205, 232 - 245.

Parson, W.W., Chu, Z.T. and Warshel, A. (1990) Biochim. Biophys. Acta 1017, 251 272.

Rees, D.C., Komiya, H., Yeates, T.O., Allen, J.P. and Feher, G. (1989) Annu. Rev. Biochem., 58, 607 - 633.

Robert, B., Lutz, M. and Tiede, D.M. (1985) FEBS Lett., 183, 326 - 330.

Schenck, C., Brasher, B., Martin, K. and Gaul, D.(1989) Abstracts VIIIth International Congress on Photosynthesis. Physiologia Planatarum ,76, A35.

Shiozawa, J.A., Lottspeich, F., Oesterhelt, D. and Feick, R. (1989) Eur. J. Biochem., 180, $75-84$.

Stanssens, P., Opsomer, C., McKeown, Y.M., Kramer, W., Zabeau, M. and Fritz, H.J. (1989) Nuc. Acids Res., 17, 4441 - 4454.

Stilz, H.U., Finkele, U., Holzapfel, W., Lauterwasser, C., Zinth, W. and Oesterhelt, D. (1990) Biochem. (submitted)

Straley, S.C., Parson, W.W., Mauzerall, D.C. and Clayton, R.K. (1973) Biochim Biophys. Acta , 305, 597 - 609.

Tiede, D.M., Budil, D.E., Tang, J., El-Kabbani, O., Norris, J.R., Chang, C.H. and Schiffer, M. (1988) In J. Breton and A. Vermeglio (eds.) The Photosynthetic Bacterial Reaction Center, Structure and Dynamics. Plenum Press, New York, pp. 13 - 20. 
van Grondelle, R., Bergström, H., Sundström, V. and Gillbro, T. (1987) Biochem. Biophys. Acta, 894, 313 - 326.

Williams, J.C., Steiner, L.A. and Feher, G. (1986) Proteins, 1, 312 - 325. 